Prepared for the U.S. Department of Energy

Under Contract DE-AC05-76RL01830

\title{
Technetium Waste Form Development- Progress Report
}

\author{
DS Gelles RJ Seffens \\ RM Ermi CE Chamberlin \\ EC Buck
}

January 2009

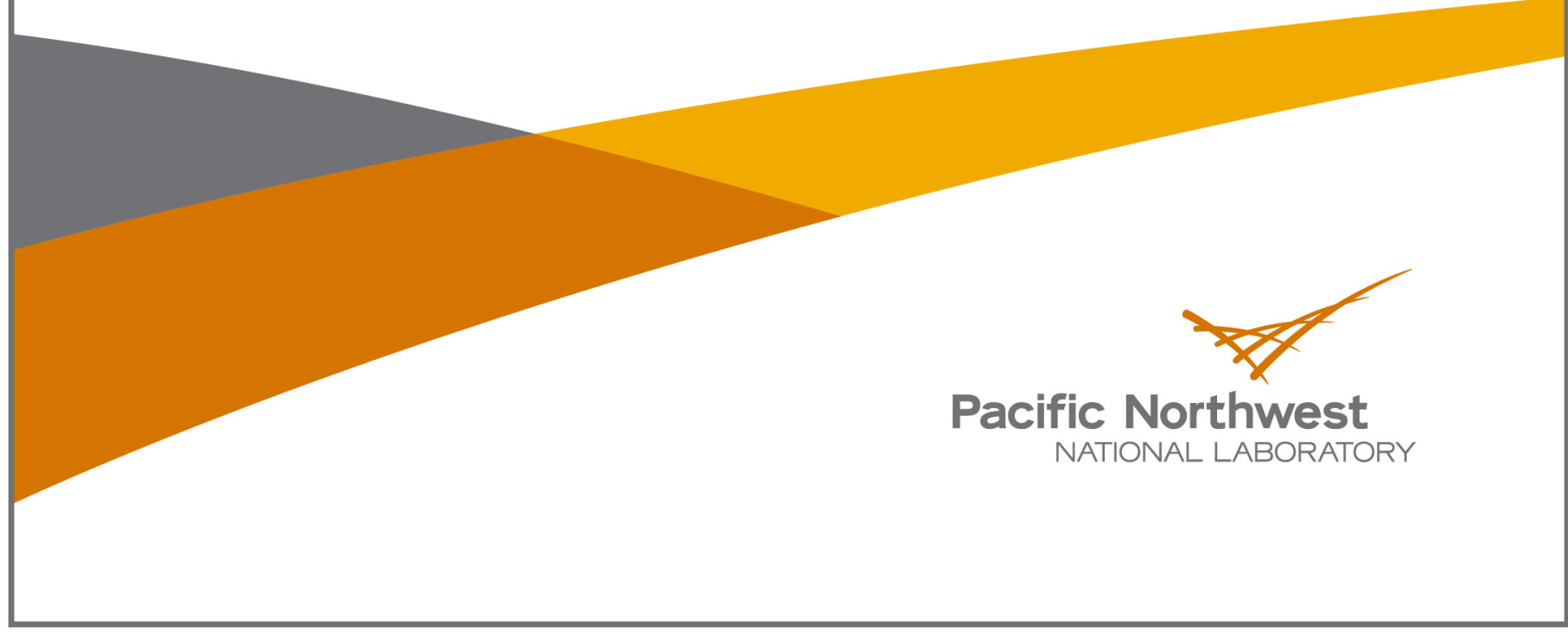




\title{
DISCLAIMER
}

This report was prepared as an account of work sponsored by an agency of the United States Government. Neither the United States Government nor any agency thereof, nor Battelle Memorial Institute, nor any of their employees, makes any warranty, express or implied, or assumes any legal liability or responsibility for the accuracy, completeness, or usefulness of any information, apparatus, product, or process disclosed, or represents that its use would not infringe privately owned rights. Reference herein to any specific commercial product, process, or service by trade name, trademark, manufacturer, or otherwise does not necessarily constitute or imply its endorsement, recommendation, or favoring by the United States Government or any agency thereof, or Battelle Memorial Institute. The views and opinions of authors expressed herein do not necessarily state or reflect those of the United States Government or any agency thereof.

\author{
PACIFIC NORTHWEST NATIONAL LABORATORY \\ operated by \\ BATTELLE \\ for the \\ UNITED STATES DEPARTMENT OF ENERGY \\ under Contract DE-AC05-76RL01830
}




\title{
Technetium Waste Form Development -Progress Report
}

\author{
DS Gelles RJ Seffens \\ RM Ermi CE Chamberlin \\ EC Buck
}

January 2009

Prepared for

the U.S. Department of Energy under Contract DE-AC05-76RL01830

Pacific Northwest National Laboratory

Richland, Washington 99352 



\begin{abstract}
This project has focused on the immobilization of Tc waste streams and undissolved solids (UDS) which consists mainly of the 5-metal particles (Mo-Ru-Tc-Rh-Pd). Composition of UDS will have strong impact on composition of the final waste form alloy. Idaho National Laboratory (INL) has added Re and Mo (as surrogates for Tc and UDS metals) to the SS-15Zr alloy that was previously developed for EBR-II metal wastes.

Microanalysis using scanning electron microscopy (SEM) and transmission electron microscopy (TEM) has been used to analyze a $\sim 5 \mathrm{~g}$. ingot with composition $71.3 \mathrm{wt} \% 316 \mathrm{SS}-5.3 \mathrm{wt} \% \mathrm{Zr}-13.2 \mathrm{wt} \%$ Mo-4.0 wt $\%$ Rh-6.2 wt\% Re prepared at the Idaho National Laboratory. Four phase fields have been identified, two of which are lamellar eutectics, with a fifth possibly present. A Zr rich phase was found distributed as fine precipitate, $\sim 10 \mu \mathrm{m}$ in diameter, often coating large cavities. A Mo-Fe-Re-Cr lamellar eutectic phase field appears as blocky regions $\sim 30 \mu \mathrm{m}$ in diameter, surrounded by a Fe-Mo-Cr lamellar eutectic phase field, and that in turn is surrounded by a $\mathrm{Zr}-\mathrm{Fe}-\mathrm{Rh}-\mathrm{Mo}-\mathrm{Ni}$ phase field. The eutectic phase separation reactions are different. The Mo-Fe-Re-Cr lamellar eutectic appears a result of austenitic steel forming at lower volume fraction within an Mo-Fe-Re intermetallic phase, whereas the Fe-Mo-Cr lamellar eutectic may be a result of the same intermetallic phase forming within a ferritic steel phase. Cavitation may have arisen either as a result of bubbles, or from loss of equiaxed particles during specimen preparation.
\end{abstract}





\section{Acknowledgments}

The authors want to thank the following individuals and organizations for their contribution to this work:

- Part of this work was performed on the Radiochemical Processing Laboratory 300keV Tecnai 30STwin Transmission Electron Microscope.

- Mr. James E. Buelt for managing the Global Nuclear Energy Partnership Program at the Pacific Northwest National Laboratory and providing support in this project.

- Ms. Susan Arey for editorial support. 



\section{Acronyms and Abbreviations}

\begin{tabular}{ll} 
CBN & cubic boron nitride \\
EBR-II & Experimental breeder reactor (II) \\
EDS & energy dispersive X-ray spectroscopy \\
eV & electron volt \\
g & grams \\
GNEP & Global Nuclear Energy Partnership \\
HLW & high-level waste \\
INL & Idaho National Laboratory \\
keV & kilo-electron volt \\
mg & milligram \\
MAWS & minimum additive waste stabilization \\
nm & nanometer \\
PNNL & Pacific Northwest National Laboratory \\
SEM & scanning electron microscopy \\
SS & stainless steel \\
TEM & transmission electron microscopy \\
XRD & x-ray diffraction \\
UDS & undissolved solids (metallic Mo-Ru-Tc-Rh-Pd phases) \\
wt\% & weight percent \\
$\mu \mathrm{m}$ & micrometer \\
\hline
\end{tabular}





\section{Contents}

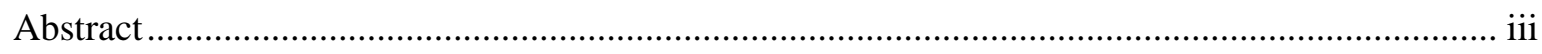

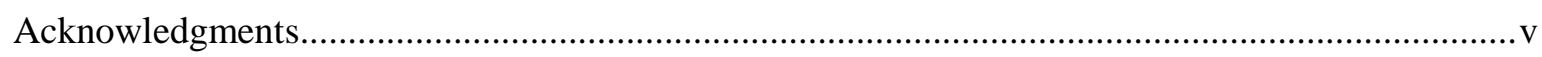



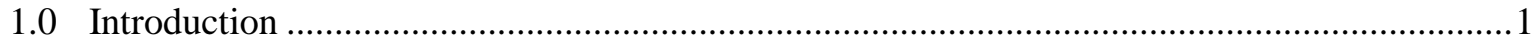



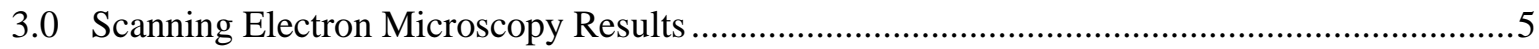

4.0 Transmission Electron Microscopy Results ......................................................................... 16

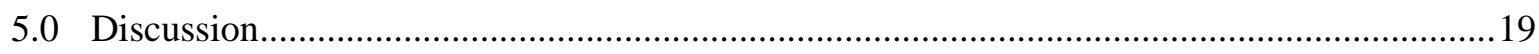

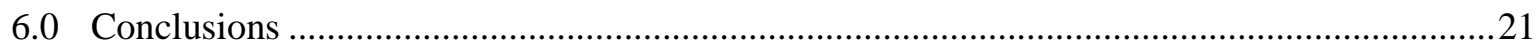

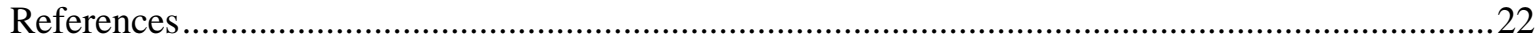




\section{Figures}

Figure 1-1 Fe-Zr phase diagram (taken from Jiang et al. 2001) 2

Figure 3-1 Mosaic of the ingot structure at low magnification in electron backscatter mode. The slag region is on the right but is not shown.

Figure 3-2. Area 1 selected for compositional analysis, with results for each site of interest given in Table 3-1 (Area 1)

Figure 3-3. Area 2 selected for compositional analysis, with results for each site of interest given in Table 3-1 (Area 2) 7

Figure 3-4 Area 3 selected for compositional analysis, with results for each site of interest given in Table 3-1 (Area 3)

Figure 3-5. Area 4 selected for compositional analysis, with results for each site of interest given in Table 3-1 (Area 4)

Figure 3-6 Composition map showing an image at higher magnification with maps for $\mathrm{Fe}, \mathrm{Cr}$, $\mathrm{Zr}, \mathrm{Mo}, \mathrm{Rh}, \mathrm{Re}$ and Ni.

Figure 3-7. A second composition map showing an image at higher magnification with maps for $\mathrm{Fe}, \mathrm{Cr}, \mathrm{Zr}, \mathrm{Mo}, \mathrm{Rh}, \mathrm{Re}$ and Ni. A crack in the sample can be noted at right center. ................ 14

Figure 4-1 A region selected for examination with moderate Mo levels...................................... 16

Figure 4-2 A second region with more complex chemistry selected for examination...................17

Figure 5-1 Colorized map showing the separation of lamellar eutectic (red-green), Fe-Mo-Cr eutectic (light green), Zr-rich phase (blue), Rh-Ni-Mo-Zr-Fe phase (dark green region, and a pore (black) in the INL Alloy 


\section{Tables}

Table 1-1 Results on Structure and Composition of Phases found in SS-15Zr Alloys.....................2

Table 3-1 Results of composition analysis (in wt\%) on the selected areas (1\&2) of interest shown

in Figure 3-2 through Figure 3-5 ................................................................................ 10

Table 3-2 Results of composition analysis (in wt \%) on the selected areas (3\&4) of interest shown

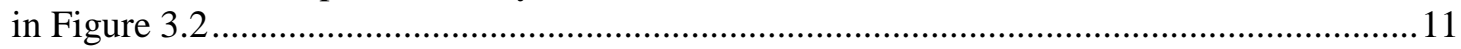

Table 3-3. Results of composition analysis for the major areas in Figures 3.3 and 3.4................ 15

Table 4-1 Results from TEM compositional analysis (wt \%) ...................................................... 17 



\subsection{Introduction}

Recycling of spent nuclear fuel potentially offers some distinct advantages over direct disposal, but environmental issues associated with the waste forms created are not likely to disappear. While these advanced waste forms will occupy considerably smaller volumes and provide much greater chemical purity than previously developed waste forms, a repository will still be required for their disposal, whether this be in the form of a geological repository for long-term storage or a surface facility for storage over the relatively shorter term. The use of a repository for long term storage of these wastes implies that the behavior of the advanced waste forms needs to be rigorously evaluated in terms of the full range of environmental conditions that are possible within the repository setting. Changes in environmental conditions are expected, and may originate from the waste forms themselves (e.g., heat, radiation damage, waste form corrosion), or may reflect the natural variability of the repository setting (e.g., water seepage rates, mechanical stability). In some cases, the environmental setting may directly reflect the durability of the waste form itself. These observations imply that waste form durability must be considered within the context of the environmental setting in which they are placed. Laboratory experiments over a range of environmental conditions are required to test the durability of the waste forms; however, these will not be sufficient to assess the behavior of the waste forms in the complex, coupled environment of a repository over long time periods. It is important to have a good understanding of the microstructure of the waste forms to develop effective long-term models for corrosion and to build scientific basis for the disposal strategy.

This project has focused on the immobilization of Tc waste streams and undissolved solids (UDS) which consists mainly of the 5-metal particles (Mo-Ru-Tc-Rh-Pd). It is likely that actual processed spent fuels will be contamination with phases such as $\mathrm{Zr}\left(\mathrm{MoO}_{4}\right)_{2} \cdot 2 \mathrm{H}_{2} \mathrm{O}$ and undissolved $\mathrm{Pu}$. The composition of UDS will have strong impact on composition of the final waste form alloy. Idaho National Laboratory (INL) has added Re (as surrogate for Tc) to the stainless steel (SS)-15Zr alloy that was developed for the EBR-II metal wastes (Abraham et al. 1997; Keiser et al. 2000; McDeavitt et al. 1998). A minimum additive waste stabilization (MAWS) approach is being utilized in waste form development that aims to produce a metal waste form product that both addresses the performance acceptance requirements and minimizes the amount of additional materials that needed to be added to make a quality waste form.

Vapor hydration testing of SS-15Zr EBR-II metallic waste forms demonstrated that only a thin 10-40 nm layer of hematite formed with segregation of $\mathrm{Zr}$, and $\mathrm{Cr}$ underneath this layer (Abraham and Dietz, 2002). These studies indicated that intermetallic components of the metallic waste form were extremely corrosion resistant suggesting any incorporated radionuclides would be retained. Elucidation of the disposition of Tc and metal fission product surrogates in a metallic waste form provides important information for predicting the long-term behavior of these materials in a disposal environment.

The EBR-II SS-15Zr composition is near-eutectic between an iron-based solid solution phase and a Laves-type intermetallic with a melt temperature of $\sim 1330^{\circ} \mathrm{C}$. The $\mathrm{Zr}$-rich side of the $\mathrm{Fe}-\mathrm{Zr}$ binary phase diagram (the Zr-8SS composition) contains primary zirconium metal $(\alpha-\mathrm{Zr})$ and several other intermetallic phases (e.g., $\mathrm{Zr}_{3} \mathrm{Fe}$ ). It has a solidus temperature between $900^{\circ} \mathrm{C}$ and $1000^{\circ} \mathrm{C}$, and the liquid temperature $\sim 1500^{\circ} \mathrm{C}$. The scanning electron microscopy (SEM) images of the SS-15Zr microstructure are dominated by two contrasting phases; a dark ferritic iron $(\alpha-\mathrm{Fe})$ and a white intermetallic phase that has been described as $\mathrm{Zr}(\mathrm{Fe}, \mathrm{Cr}, \mathrm{Ni})_{2+\mathrm{x}}(\mathrm{McD}$ eavitt et al. 1998 and Figure 1-1). The dark phase has been found to be a combination of ferritic $\alpha$-Fe and austenitic $\gamma$-Fe depending on the nickel content of the starting steel and the zirconium content. The intermetallic tends to be a strong sink for nickel. A second $\mathrm{Zr}-\mathrm{Fe}$ compound, $\mathrm{Zr}_{6} \mathrm{Fe}_{23}$, has been identified with neutron diffraction (Abraham et al. 1997). In experiments where metallic fission products have been added, these have typically resided in the intermetallic phases. Molybdenum was identified as preferring the $\alpha$-Fe phase; however, it tends to be 
present in all phases. Likewise, studies by Keiser et al. (2000) have demonstrated that Tc when added to the EBR-II metallic waste form SS-15Zr composition, results in the slight alteration of all lattice parameters, suggesting that Tc is also incorporated into all phases in the alloy. As Tc is a larger ion than $\mathrm{Fe}, \mathrm{Cr}$, or $\mathrm{Ni}$, the introduction of $\mathrm{Tc}$ results in a slight expansion of the lattice parameters. The lattice parameters and compositions based on SEM - x-ray energy dispersive spectroscopy (EDS) analysis from SS-15Zr are shown in Table 1-1. Neutron diffraction analysis of Tc-doped SS-15Zr alloys indicated a 0.08 to $0.25 \%$ change in the lattice parameters (Keiser et al. 2000, Table 2, pg 335). It is interesting to note that such small changes in the structure would probably not be detectable by either conventional $\mathrm{x}$ ray or electron diffraction methods.

Table 1-1 Results on Structure and Composition of Phases found in SS-15Zr Alloys

\begin{tabular}{|l|l|c|c|c|c|}
\hline Phase and structure & Lattice Parameters $(\mathrm{nm})$ & \multicolumn{3}{|l|}{ Phase Elemental Analysis (At\%) } \\
\hline & & $\mathrm{Fe}$ & $\mathrm{Cr}$ & $\mathrm{Ni}$ & $\mathrm{Zr}$ \\
\hline Ferrite $(b c c)$ & $\mathbf{a}=0.2876$ & 67 & 25 & 5 & $<0.1$ \\
\hline Austenite $(f c c)$ & $\mathbf{a}=0.3596$ & 71 & 19 & 7 & $<0.1$ \\
\hline Laves C36 & $\mathbf{a}=0.4908, \mathbf{c}=1.6016$ & 54 & 7 & 12 & 24 \\
\hline Laves C15 & $\mathbf{a}=0.6938$ & -- & -- & -- & -- \\
\hline$(\mathrm{Fe}, \mathrm{Cr}, \mathrm{Ni})_{23} \mathrm{Zr}_{6}$ & $\mathbf{a}=1.1690$ & 58 & 10 & 9 & 20 \\
\hline
\end{tabular}

Notes: Taken from Abraham et al. (1997), Table 2, pg 660

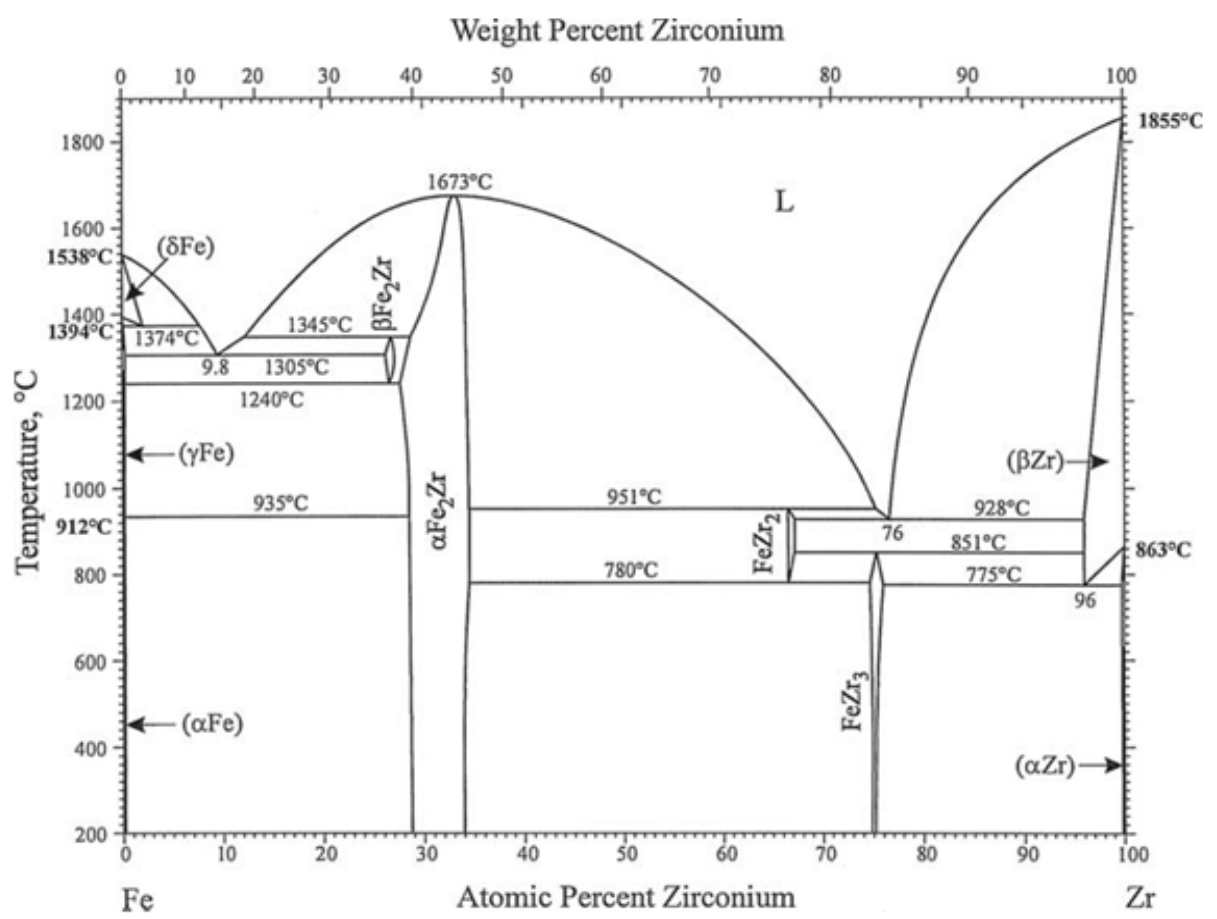

Figure 1-1 Fe-Zr phase diagram (taken from Jiang et al. 2001) 
This report documents the results of analysis on a $\sim$ g ingot prepared on 5/27/2008 at Idaho National Laboratory (INL). The ingot composition was defined as $71.3 \mathrm{wt} \% 316 \mathrm{SS}-5.3 \mathrm{wt} \% \mathrm{Zr}-13.2 \mathrm{wt} \% \mathrm{Mo}-4.0$ wt\% Rh-6.2 wt\% Re. The much higher molybdenum content in this new waste form alloy composition suggests that comparison with a binary Fe-Mo may be a more appropriate first approximation to the system rather than the Fe-Zr system. The equilibrium phase diagram of the Fe-Mo system presents very narrow regions of bcc solid solutions at $700^{\circ} \mathrm{C}$. At this temperature about 2.5 at. $\%$ of Mo dissolves in the iron lattice forming an $\mathrm{Fe}(\mathrm{Mo})$ solid solution and only about 0.5 at.\% of iron dissolves in the molybdenum lattice forming a $\mathrm{Mo}(\mathrm{Fe})$ solid solution (Jartych et al. 2002). 


\subsection{Materials and Methods}

The $\sim 5 \mathrm{~g}$ ingot was prepared on 5/27/2008 at INL with a defined composition of $71.3 \mathrm{wt} \% 316 \mathrm{SS}-5.3$ wt $\% \mathrm{Zr}-13.2 \mathrm{wt} \% \mathrm{Mo}-4.0 \mathrm{wt} \% \mathrm{Ru}-6.2 \mathrm{wt} \% \mathrm{Re}$. The ingot was prepared both for analytical SEM and analytical TEM. For SEM, a section of the ingot was prepared as a metallographic mount and final polished on a vibratory Syntron, first with one micrometer diamond on a nylon lapping cloth and then with colloidal silica on a super fine felt cloth. For TEM, 3-mm diameter slices were diamond polish dimpled (first with 6-micron diamond paste and then with 0 to $2 \mu \mathrm{m}$ cubic boron nitride (CBN) and ion milled using standard Gatan procedures. The metallic waste form sample was extremely brittle and during the first TEM sample preparation attempt, the thin-foil broke during handling. A second specimen was epoxy impregnated prior to final polishing and ion milling.

SEM analysis was performed on a JEOL JSM-840 operating at $20 \mathrm{keV}$ with Oxford Instruments INCA analysis software and TEM analysis was performed on the Radiochemical Processing Laboratory Tecnai 30S-Twin operating at $300 \mathrm{keV}$ with EMiSPEC software and a Gatan ORIUS digital camera with DigitalMicrograph software. 


\subsection{Scanning Electron Microscopy Results}

The ingot at low magnification is shown as a mosaic in Figure 3.1. The images were taken in electron backscatter mode so that heavier elements show brighter. The mosaic provides examples of linear structures $\sim 500 \mu \mathrm{m}$ in length typical of dendrites formed during solidification, and a number of circular black features that were later determined to be holes caused by polishing drop-outs. This microstructure would be typical for a SS-15Zr material where the dark portion is typically iron rich and the light material is a zirconium-bearing intermetallic (McDeavitt et al., 1998; Abraham et al., 1997). However, in this case, molybdenum was a more dominant constituent than zirconium and the intermetallic phase had a composition that was Mo-rich.

A series of four areas were selected to determine compositions for specific features, with the relevant images in Figure 3.2 through Figure 3- and the results in Table 3.1.



Figure 3-1 Mosaic of the ingot structure at low magnification in electron backscatter mode. The slag region is on the right but is not shown.

The backscattered contrast image (see Figure 3-1) of the ingot reveals a eutectic microstructure containing an iron solid solution (dark), an intermetallic (bright), and large pores. The nature of these components were further explored with SEM-EDS. The pores ranged in size from $50 \mu \mathrm{m}$ to $200 \mu \mathrm{m}$. 


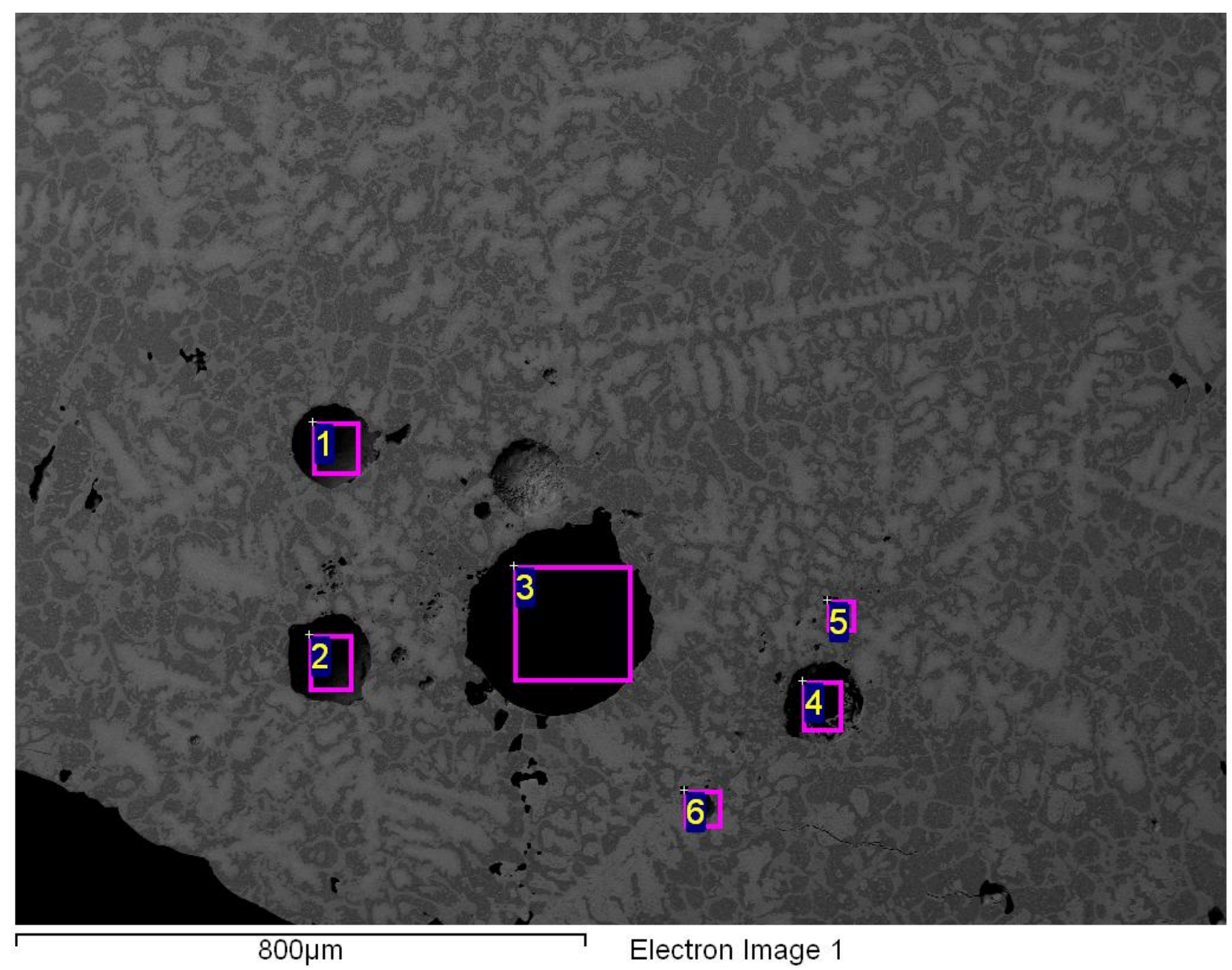

Figure 3-2. Area 1 selected for compositional analysis, with results for each site of interest given in Table 3-1 (Area 1) 
Area 2

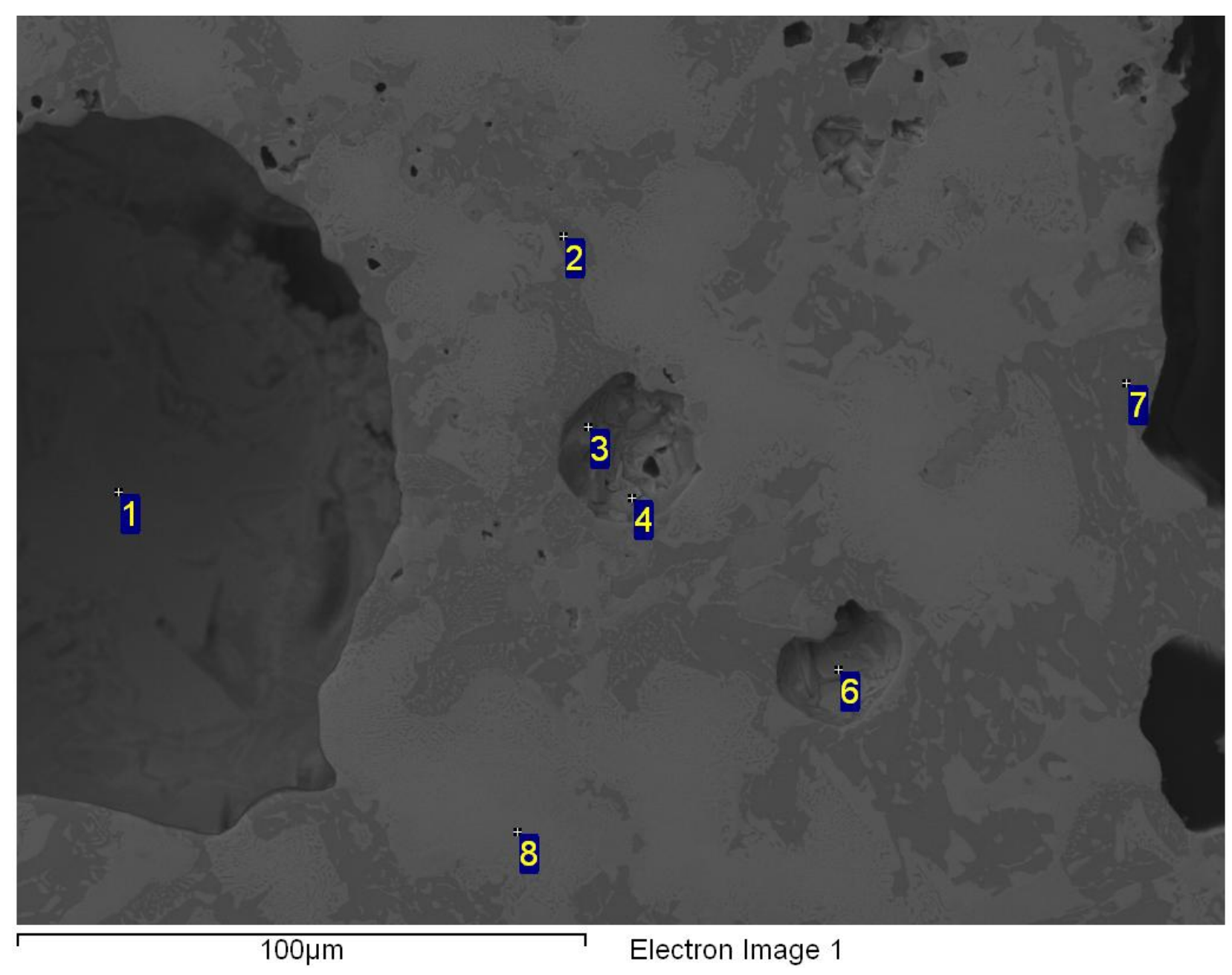

Figure 3-3. Area 2 selected for compositional analysis, with results for each site of interest given in Table 3-1 (Area 2) 
Area 3

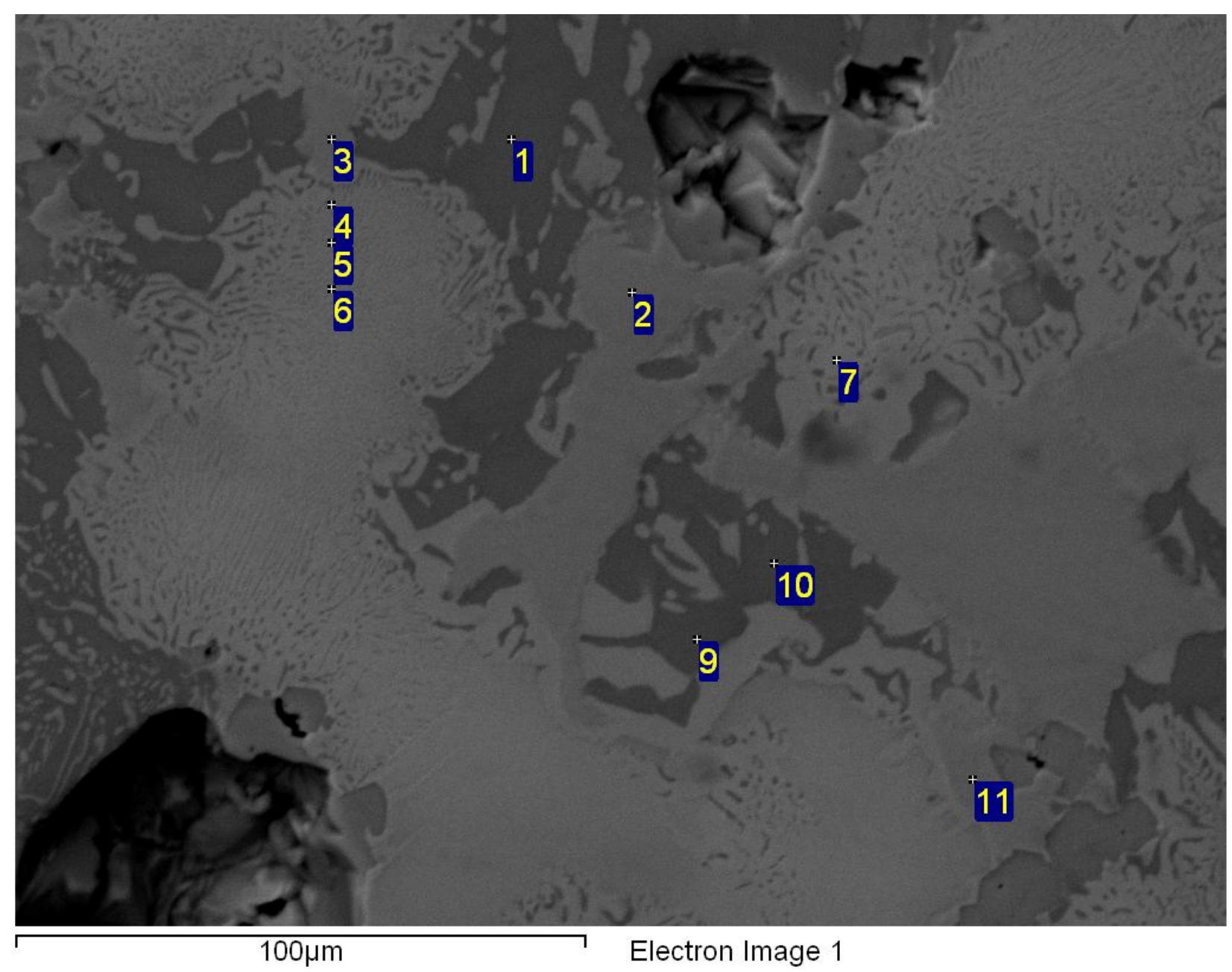

Figure 3-4 Area 3 selected for compositional analysis, with results for each site of interest given in Table 3-1 (Area 3) 
Area 4



Figure 3-5. Area 4 selected for compositional analysis, with results for each site of interest given in Table 3-1 (Area 4) 
Table 3-1 Results of composition analysis (in wt $\%$ ) on the selected areas (1\&2) of interest shown in Figure 3-2 through Figure 3-5

Area 1 (Figure 3-2)

\begin{tabular}{|c|c|c|c|c|c|c|c|c|}
\hline Spectrum & $\mathrm{Cr}$ & $\mathrm{Fe}$ & $\mathrm{Ni}$ & $\mathrm{Zr}$ & Mo & $\mathrm{Rh}$ & $\mathrm{Re}$ & Total \\
\hline 1 & 0.4 & 6.9 & 0.9 & 89.1 & 2.1 & 0.6 & 0.0 & 100.0 \\
\hline 2 & 2.3 & 13.2 & 2.2 & 68.2 & 8.3 & 5.8 & 0.0 & 100.0 \\
\hline 3 & 5.0 & 27.3 & $\overline{7.0}$ & 32.7 & 22.6 & 5.5 & 0.0 & 100.0 \\
\hline 4 & 0.6 & 3.7 & 0.9 & 91.3 & 2.1 & 1.4 & 0.0 & 100.0 \\
\hline 5 & 5.4 & 30.6 & 4.3 & 37.5 & 16.2 & 6.0 & 0.0 & 100.0 \\
\hline 6 & 7.5 & 36.9 & 4.5 & 23.6 & 23.3 & 4.2 & 0.0 & 100.0 \\
\hline Mean & 3.5 & 19.8 & 3.3 & 57.1 & 12.4 & 3.9 & & \\
\hline Std. dev. & 2.9 & 13.7 & 2.4 & 29.7 & 9.6 & 2.4 & & \\
\hline Max. & 7.5 & 36.9 & 7.0 & 91.3 & 23.3 & 6.0 & & \\
\hline Min. & 0.4 & 3.7 & 0.9 & 23.6 & 2.1 & 0.6 & & \\
\hline \multicolumn{9}{|c|}{ Area 2 (Figure 3-3) } \\
\hline Spectrum & $\mathrm{Cr}$ & $\mathrm{Fe}$ & $\mathrm{Ni}$ & $\mathrm{Zr}$ & Mo & $\overline{\mathrm{Rh}}$ & $\mathrm{Re}$ & Total \\
\hline 1 & 3.1 & 14.1 & 2.3 & 68.7 & 8.0 & 3.9 & 0.0 & 100.0 \\
\hline 2 & 9.8 & 60.1 & 7.7 & 0.2 & 11.5 & 6.3 & 4.4 & 100.0 \\
\hline 3 & 0.1 & 0.9 & 0.1 & 97.8 & 0.0 & 0.0 & 1.7 & 100.5 \\
\hline 4 & 4.2 & 21.8 & 2.7 & 50.5 & 15.6 & 1.8 & 3.5 & 100.0 \\
\hline 5 & 4.3 & 27.6 & 4.3 & 59.7 & 1.0 & 2.0 & 1.1 & 100.0 \\
\hline 6 & 4.2 & 27.8 & 4.6 & 59.7 & 1.0 & 1.6 & 1.1 & 100.0 \\
\hline 7 & 9.7 & 58.8 & 7.9 & 0.0 & 13.3 & 6.1 & 4.5 & 100.3 \\
\hline 8 & 8.7 & 32.8 & 2.7 & 0.0 & 36.5 & 3.2 & 16.3 & 100.1 \\
\hline Mean & 5.5 & 30.5 & 4.0 & 42.1 & 10.9 & 3.1 & 4.6 & \\
\hline Std. dev. & 3.5 & 20.4 & 2.7 & 37.4 & 12.0 & 2.2 & 5.3 & \\
\hline Max. & 9.8 & 60.1 & 7.9 & 97.8 & 36.5 & 6.3 & 16.3 & \\
\hline Min. & 0.1 & 0.9 & 0.1 & 0.0 & 0.0 & 0.0 & 1.1 & \\
\hline
\end{tabular}


Table 3-2 Results of composition analysis (in wt\%) on the selected areas (3\&4) of interest shown in Figure 3.2

\begin{tabular}{|c|c|c|c|c|c|c|c|c|}
\hline \multicolumn{9}{|c|}{ Area 3 (Figure 3-4) } \\
\hline Spectrum & $\mathrm{Cr}$ & $\mathrm{Fe}$ & $\mathrm{Ni}$ & $\mathrm{Zr}$ & Mo & $\mathrm{Rh}$ & $\operatorname{Re}$ & Total \\
\hline 1 & 9.6 & 57.7 & 7.9 & 0.2 & 14.4 & 5.9 & 4.4 & 100.0 \\
\hline 2 & 2.5 & 24.9 & 8.5 & 32.7 & 14.1 & 16.7 & 0.6 & 100.0 \\
\hline 3 & 2.5 & 24.8 & 8.9 & 32.7 & 13.9 & 17.3 & 0.0 & 100.1 \\
\hline 4 & 9.2 & 35.7 & 2.9 & 0.0 & 36.9 & 2.4 & 13.1 & 100.2 \\
\hline 5 & 8.7 & 32.8 & 2.6 & 0.3 & 37.7 & 3.2 & 14.7 & 100.0 \\
\hline 6 & 8.7 & 33.1 & 3.0 & 0.0 & 37.1 & 2.0 & 16.1 & 100.1 \\
\hline 7 & 7.9 & 29.2 & 2.2 & 0.9 & 41.8 & 1.6 & 16.5 & 100.0 \\
\hline 8 & 10.4 & 61.0 & 7.1 & 0.2 & 12.0 & 5.9 & 3.6 & 100.0 \\
\hline 9 & 10.2 & 61.0 & 7.3 & 0.1 & 11.9 & 6.0 & 3.6 & 100.0 \\
\hline 10 & 10.0 & 59.6 & 7.6 & 0.0 & 13.0 & 5.9 & 4.2 & 100.2 \\
\hline 11 & 2.4 & 24.6 & 9.1 & 32.9 & 13.8 & 17.1 & 0.2 & 100.0 \\
\hline Mean & 8.4 & 42.1 & 5.2 & 4.3 & 25.5 & 5.5 & 9.0 & \\
\hline Std. dev. & 2.6 & 15.6 & 2.8 & 11.6 & 13.9 & 5.0 & 6.7 & \\
\hline Max. & 10.4 & 61.0 & 9.1 & 32.9 & 41.8 & 17.3 & 16.5 & \\
\hline Min. & 2.4 & 24.6 & 2.2 & 0.0 & 11.9 & 1.6 & 0.0 & \\
\hline \multicolumn{9}{|c|}{ Area 4 (Figure 3-5) } \\
\hline Spectrum & $\mathrm{Cr}$ & $\mathrm{Fe}$ & $\mathrm{Ni}$ & $\mathrm{Zr}$ & Mo & $\mathrm{Rh}$ & $\overline{\operatorname{Re}}$ & Total \\
\hline 1 & 2.5 & 24.4 & 8.7 & 33.2 & 14.0 & 16.8 & 0.4 & 100.0 \\
\hline 2 & 2.6 & 24.5 & 8.8 & 33.3 & 13.9 & 16.5 & 0.3 & 100.0 \\
\hline 3 & 7.3 & 35.6 & 3.9 & 2.2 & 40.6 & 2.1 & 8.3 & 100.0 \\
\hline 4 & 2.6 & 24.9 & 8.7 & 33.0 & 14.2 & 16.3 & 0.3 & 100.0 \\
\hline 5 & 0.0 & 0.7 & 0.1 & 99.6 & 0.0 & 0.0 & 1.7 & 102.1 \\
\hline 6 & 2.5 & 24.0 & 8.7 & 33.1 & 13.8 & 17.3 & 0.6 & 100.0 \\
\hline 7 & 9.8 & 57.2 & 8.3 & 0.0 & 14.7 & 5.9 & 4.2 & 100.1 \\
\hline 8 & 1.2 & 5.6 & 0.5 & 80.2 & 8.6 & 1.1 & 2.8 & 100.0 \\
\hline Mean & 3.6 & 24.6 & 6.0 & 39.3 & 15.0 & 9.5 & 2.3 & \\
\hline Std. dev. & 3.3 & 17.4 & 3.9 & 34.6 & 11.5 & 7.9 & 2.8 & \\
\hline Max. & 9.8 & 57.2 & 8.8 & 99.6 & 40.6 & 17.3 & 8.3 & \\
\hline Min. & 0.0 & 0.7 & 0.1 & 0.0 & 0.0 & 0.0 & 0.3 & \\
\hline
\end{tabular}


From these results, the following can be shown. The dark regions of area 1, (Figure 3-2) show enriched levels for $\mathrm{Zr}$, with sites 3, 5 and 6 showing moderate $\mathrm{Fe}$ and Mo when $\mathrm{Zr}$ levels are below 50\%. Where features at the bottom of cavities are analyzed in area 2, Zr levels are again high, but sites 2, 7 and 8 for features away from those cavities show negligible Zr. In area 3 (Figure 3-4), sites 4 through 7 show enhancement of Mo, corresponding to a region imaging brightly, but relative values for $\mathrm{Fe}, \mathrm{Re}$ and $\mathrm{Rh}$ are constant from site to site. Careful examination of this region in Figure 3-4 reveals contrast typical of a lamellar eutectic, but the small variation found for $\mathrm{Fe}$, Re and $\mathrm{Rh}$ probably indicates that the lamellar spacing is too fine for SEM composition resolution. In comparison, the darker regions of sites 1 and 8 through 10, (8 duplicates 9) on Figure 3-6 are found to be rich in Fe, whereas sites 2, 3 and 11, also showing brightly, are rich in $\mathrm{Zr}$ and Fe, similar to some sites found in area 1. Sites in area 4 were selected to better understand areas showing bright versus dark contrast. Brighter sites 1, 2, 4 and 6 are found to be rich in $\mathrm{Zr}$ and $\mathrm{Fe}$, whereas site 3 is rich in Mo and Fe. Darker sites 5 and 8 are highly enriched in $\mathrm{Zr}$, but 7 is enriched in $\mathrm{Fe}$.

These results are better understood with the compositional maps shown in Figures 3-6 and 3-7. In each case, an image was collected and then the sample was scanned with complete $\mathrm{x}$-ray information collected for each pixel. The x-ray data was then analyzed for elements $\mathrm{Fe}, \mathrm{Cr}, \mathrm{Zr}, \mathrm{Mo}, \mathrm{Rh}, \mathrm{Re}$ and $\mathrm{Ni}$, and the data was mapped. The two maps appear consistent. For example, in each case maps of $\mathrm{Ni}$ and $\mathrm{Rh}$ are similar, as are Mo and $\mathrm{Re}$. Cr matches Fe, but Fe shows variations in contrast such that the darker regions match Mo. $\mathrm{Zr}$ shows strong contrast in regions matching zero contrast for $\mathrm{Fe}$, but also shows weak contrast that matches $\mathrm{Ni}$ and $\mathrm{Rh}$. It was also possible to select areas within each of the identifiable regions and collect the $\mathrm{x}$-ray data for analysis. Results are provided in Table 3-3. 

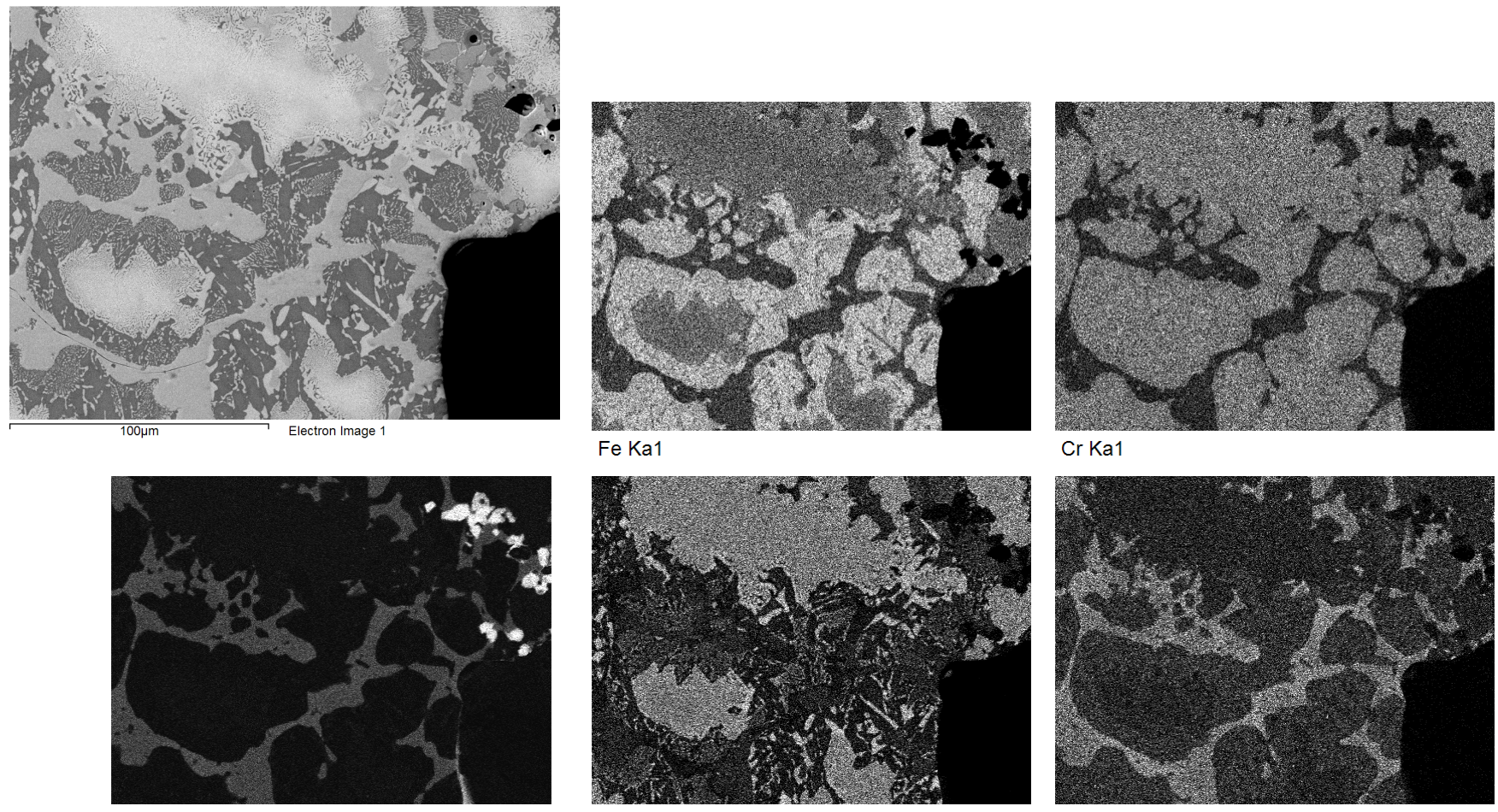

$\mathrm{Fe} \mathrm{Ka} 1$

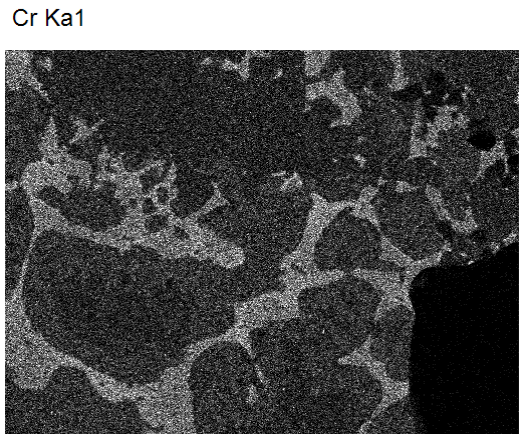

Zr La1



Mo La1

Rh La1
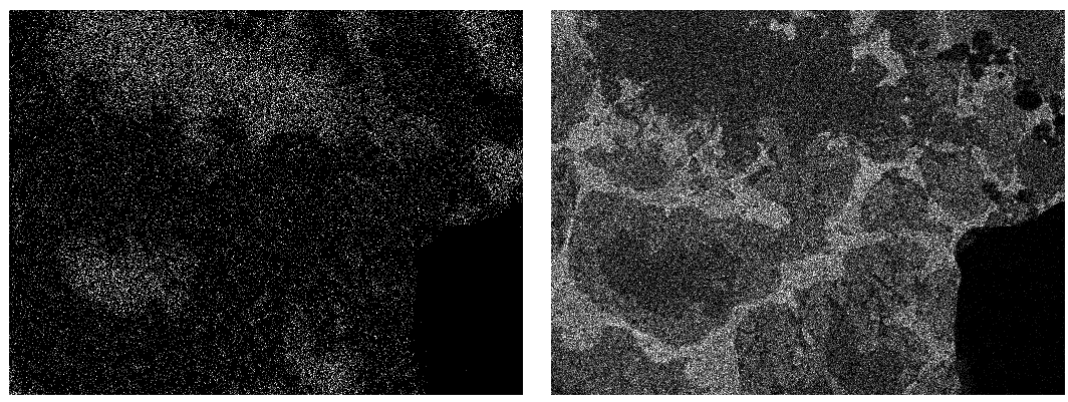

Re La1

Ni Ka1

Figure 3-6 Composition map showing an image at higher magnification with maps for $\mathrm{Fe}, \mathrm{Cr}, \mathrm{Zr}$, Mo, $\mathrm{Rh}, \mathrm{Re}$ and Ni. 

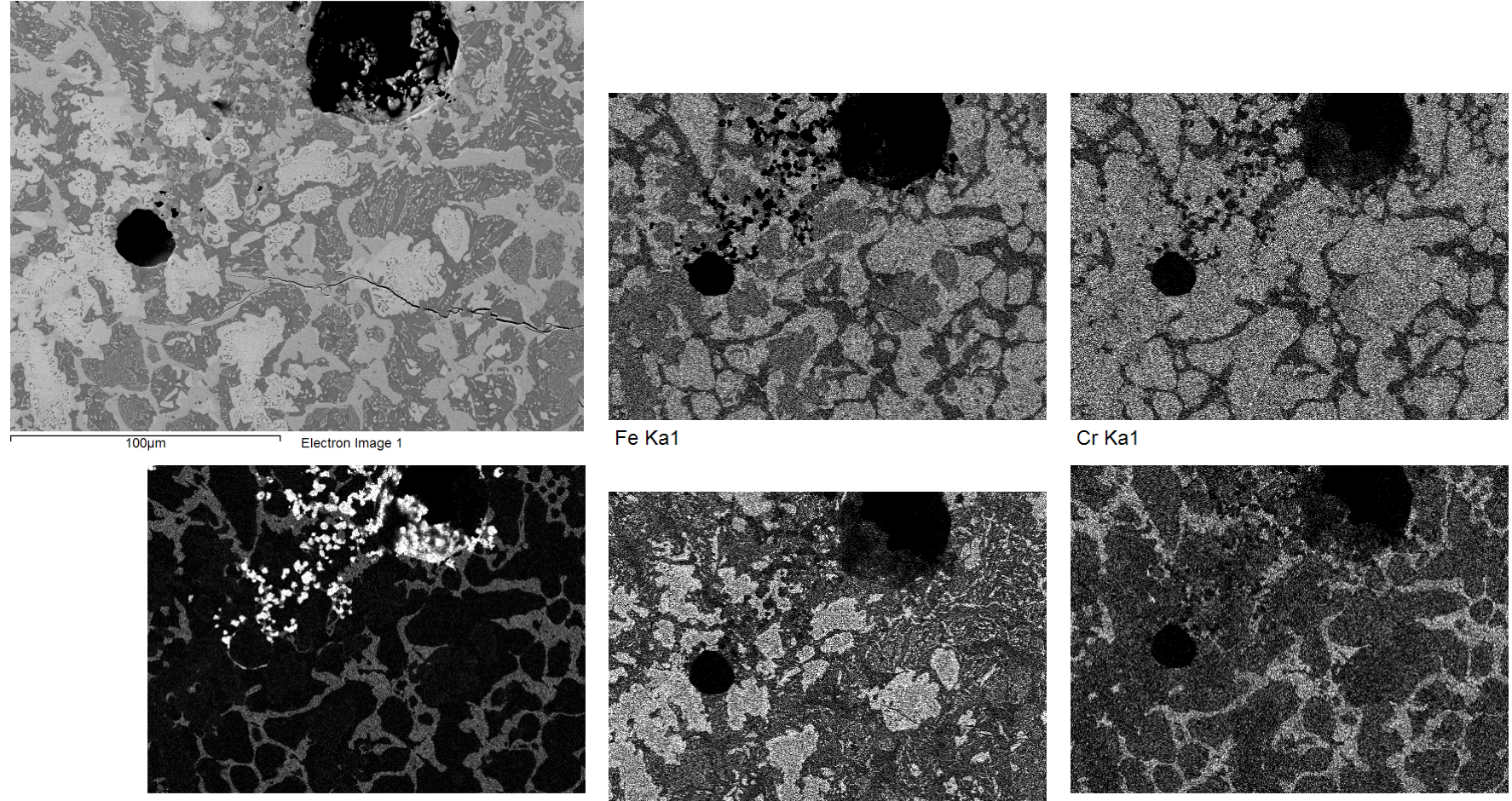

Fe Ka1


Rh La1
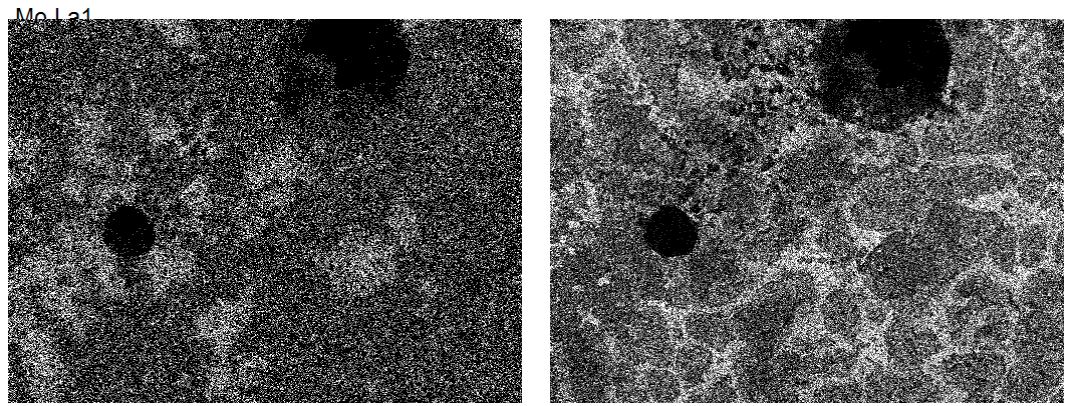

Re La1 Ni Ka1

Figure 3-7. A second composition map showing an image at higher magnification with maps for $\mathrm{Fe}, \mathrm{Cr}$, $\mathrm{Zr}, \mathrm{Mo}, \mathrm{Rh}, \mathrm{Re}$ and Ni. A crack in the sample can be noted at right center. 
Table 3-3. Results of composition analysis for the major areas in Figures 3.6 and 3.7.

\begin{tabular}{|c|c|c|c|c|c|c|c|}
\hline Phase & $\mathrm{Cr}$ & $\mathrm{Fe}$ & $\mathrm{Ni}$ & $\mathrm{Zr}$ & Mo & $\mathbf{R h}$ & $\operatorname{Re}$ \\
\hline \multicolumn{8}{|l|}{ Figure 3.6} \\
\hline $\mathrm{Mo}-\mathrm{Fe}-\mathrm{Re}-\mathrm{Cr}$ & 8.5 & 31.2 & 2.1 & 0.0 & 38.1 & 2.3 & 17.8 \\
\hline Mo-Fe-Re-Cr & 8.8 & 33.7 & 2.8 & 0.0 & 37.1 & 2.6 & 15.7 \\
\hline Fe-Mo-Cr & 9.7 & 52.9 & 6.4 & 0.0 & 20.2 & 6.1 & 4.8 \\
\hline $\mathrm{Zr}$ & 0.0 & 0.1 & 0.4 & 94.9 & 0.0 & 1.5 & 3.1 \\
\hline Zr-Fe-Rh-Mo-Ni & 2.4 & 24.6 & 9.3 & 33.0 & 14.5 & 15.5 & 0.6 \\
\hline \multicolumn{8}{|l|}{ Figure 3.7} \\
\hline Mo-Fe-Re-Cr & 9.2 & 33.6 & 2.7 & 0.0 & 37.3 & 3.0 & 14.6 \\
\hline $\mathrm{Fe}-\mathrm{Mo}-\mathrm{Cr}$ & 9.7 & 50.9 & 6.5 & 0.0 & 22.8 & 5.4 & 4.7 \\
\hline $\mathrm{Zr}$ & 0.6 & 0.8 & 0.8 & 94.2 & 0.0 & 1.4 & 2.3 \\
\hline Zr-Fe-Rh-Mo-Ni & 2.0 & 22.6 & 9.8 & 36.4 & 10.3 & 18.5 & 0.3 \\
\hline
\end{tabular}

From Table 3-3, four phases are indicated with similar results for both regions analyzed. A $\mathrm{Zr}$ rich phase contains minor additions of Re and $\mathrm{Rh}$, an Fe-Mo-Cr phase contains minor additions of all but $\mathrm{Zr}$, as does a Mo-Fe-Re-Cr, and finally a complex Zr-Fe-Rh-Mo-Ni phase contains all elements, but with very little Re. However, SEM images demonstrate that the Mo-Fe-Re-Cr is a lamellar eutectic and Figures 3-6 and 3-7 verify a similar effect in the Fe-Mo-Cr phase. The SEM did not provide sufficient resolution to analyze this eutectic response and further analysis was conducted with TEM. 


\subsection{Transmission Electron Microscopy Results}

As was found during the SEM observations, specimen preparation for TEM examination resulted in many holes in the sample. Continued ion milling produced areas between the holes sufficiently thinned for examination. Two areas were selected: the first corresponds to a Mo-Fe-Re-Cr eutectoid region, and the second includes a Fe-Mo-Cr eutectic region as well as $\mathrm{Zr}-\mathrm{Fe}-\mathrm{Rh}-\mathrm{Mo}-\mathrm{Ni}$ regions. These areas are shown in Figures 4-1 and 4-2. In each case, energy dispersive x-ray spectroscopy (EDS) spectra were taken for those locations annotated on the figure. The results of quantitative analysis are given as wt\% in Table 41. From these results, it can be shown that Figure 4-1 contains structure with significant variation in Mo, between 21 and $42 \%$. The smaller and whiter regions contain lower Mo levels, whereas the darker surrounding regions are higher in $\mathrm{Mo}$, with lower $\mathrm{Ni}$, somewhat lower $\mathrm{Zr}$, and slightly lower $\mathrm{Cr}$. Dislocation slip band structure can be identified in the region labeled 1, with similar, but less extensive bands visible in the surrounding area. Diffraction information for regions 4 and 5 indicate that the surrounding region, which is higher in Mo, is an intermetallic phase with a large lattice parameter, whereas region 5 is probably face centered cubic with a lattice parameter similar to stainless steel. Deformation is expected to be more likely in a stainless steel phase than in an intermetallic phase, as observed.

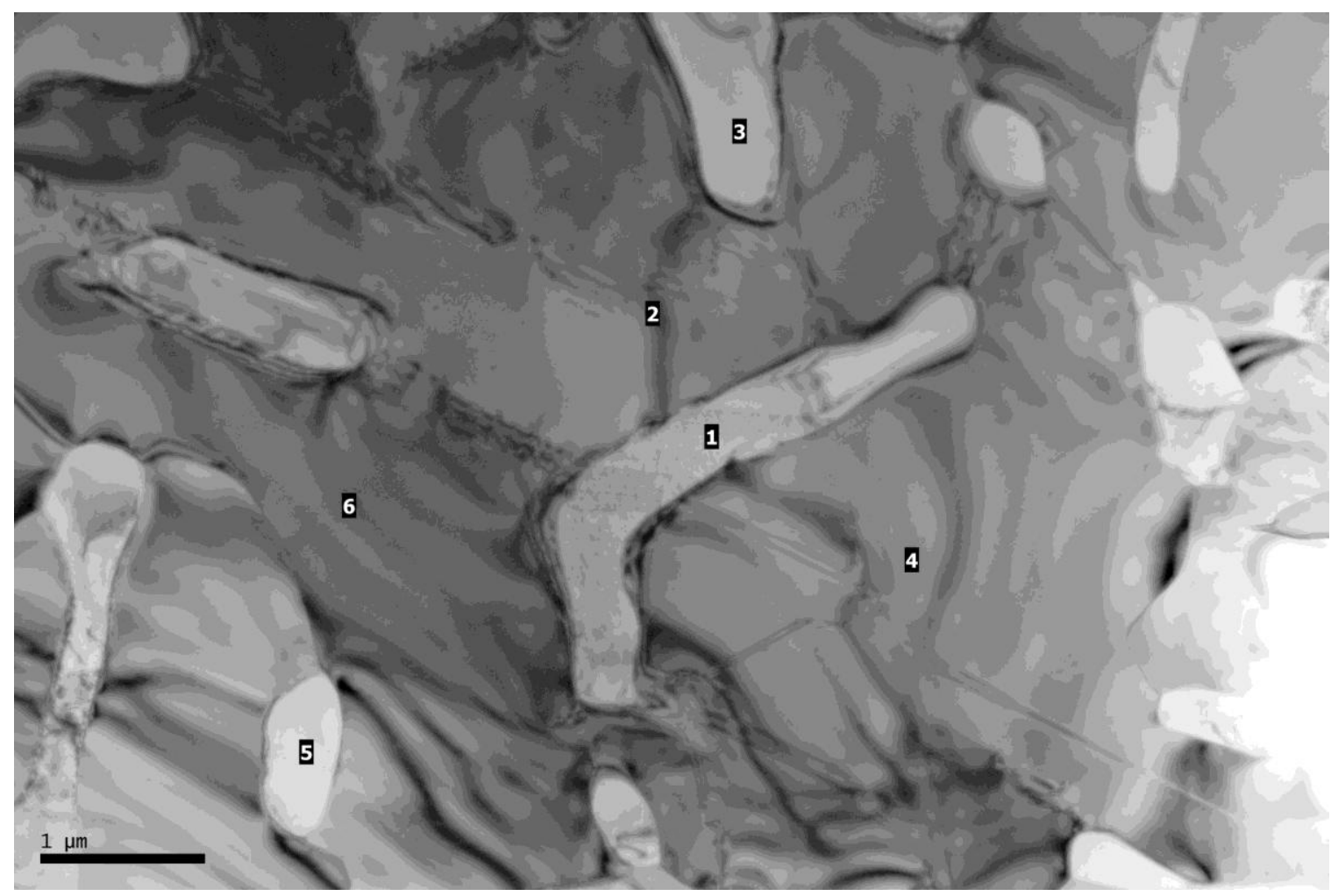

Figure 4-1 A region selected for examination with moderate Mo levels. 


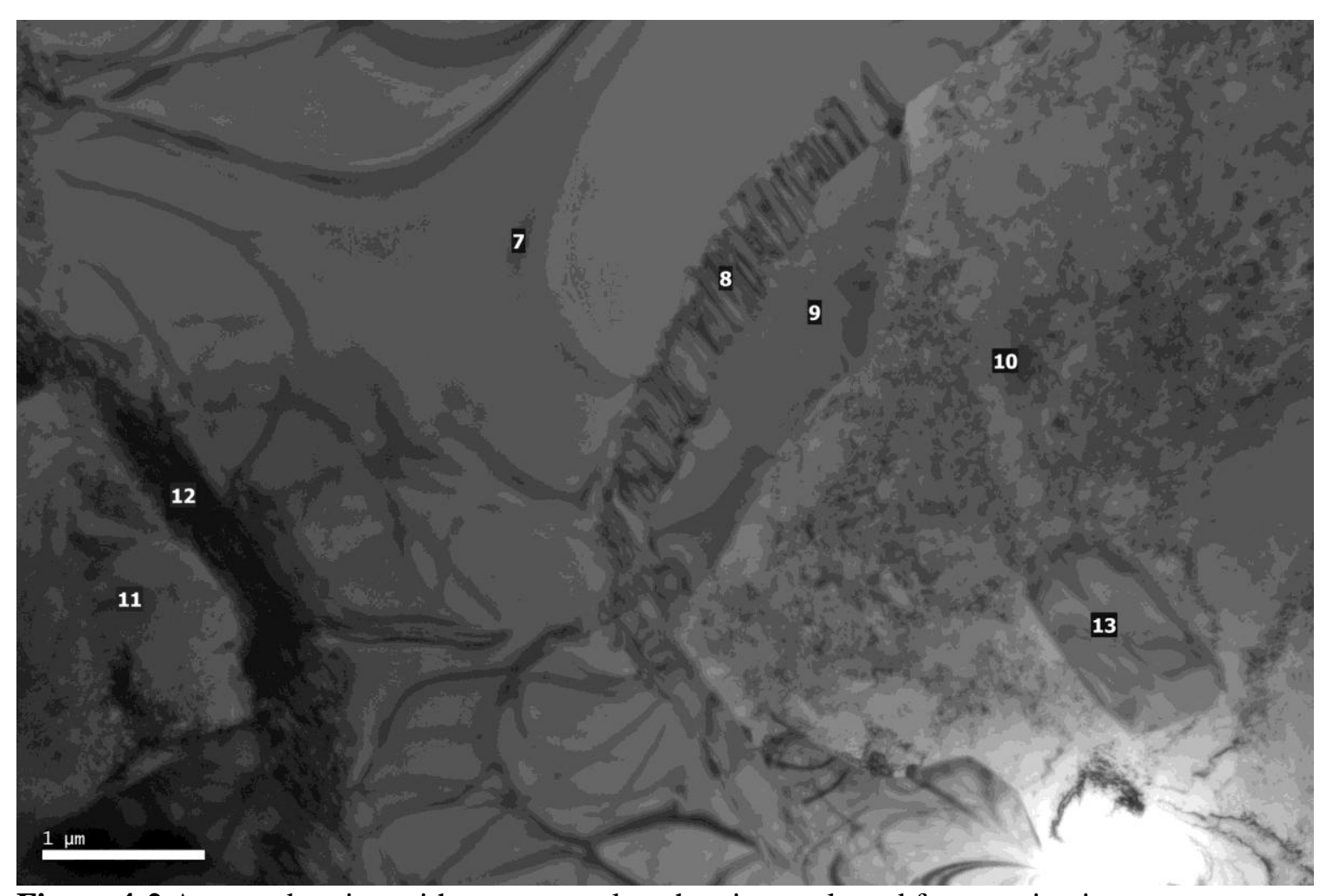

Figure 4-2 A second region with more complex chemistry selected for examination.

Table 4-1 Results from TEM compositional analysis (wt\%)

\begin{tabular}{|c|c|c|c|c|c|c|}
\hline Site & $\mathrm{Cr}(\mathrm{K})$ & $\mathrm{Fe}(\mathrm{K})$ & $\mathrm{Ni}(\mathrm{K})$ & $\mathrm{Zr}(\mathrm{K})$ & $\mathrm{Mo}(\mathrm{K})$ & $\operatorname{Re}(\mathrm{L})$ \\
\hline 1 & 7.7 & 44.5 & 5.9 & 0.6 & 27.3 & 13.9 \\
\hline 2 & 6.4 & 33.8 & 2.8 & 3.4 & 42.5 & 11.1 \\
\hline 3 & 8.2 & 53.9 & 7.3 & 2.0 & 20.8 & 7.9 \\
\hline 4 & 7.8 & 29.9 & 3.1 & 2.3 & 38.4 & 18.6 \\
\hline 5 & 8.4 & 42.3 & 7.0 & 0.0 & 33.4 & 8.9 \\
\hline 6 & 8.2 & 35.3 & 3.9 & 1.7 & 34.5 & 16.4 \\
\hline 7 & 3.1 & 31.4 & 12.6 & 29.2 & 18.7 & 5.0 \\
\hline 8 & 2.8 & 28.6 & 17.1 & 37.7 & 11.0 & 2.8 \\
\hline 9 & 7.8 & 32.8 & 3.1 & 3.1 & 40.0 & 13.2 \\
\hline 10 & 9.1 & 62.7 & 9.2 & 0.9 & 12.8 & 5.3 \\
\hline 11 & 9.8 & 64.2 & 9.1 & 1.0 & 10.8 & 5.3 \\
\hline 12 & 2.2 & 28.5 & 15.9 & 37.6 & 12.9 & 2.8 \\
\hline 13 & 7.2 & 32.5 & 2.7 & 1.8 & 44.9 & 10.8 \\
\hline
\end{tabular}

Figure 4-2 is found to contain Fe-Mo-Cr eutectic regions, labeled 10 and 11, with an example of the related eutectoid phase labeled 13. Comparison indicates that the surrounding region in this case is richer 
in $\mathrm{Fe}$ and leaner in Mo, with much lower $\mathrm{Ni}$, and somewhat lower $\mathrm{Cr}$ and Re. Deformation structure can be identified as a fine texture within the regions labeled 10 and 11, suggesting that in this case the intermetallic is the eutectoid phase in a ferritic/martensitic steel matrix, but crystallographic information is not yet available to confirm this suggestion. The remaining phases in Figure 4.2 can be related to our earlier conclusions as follows. The phase labeled 9 is rich in Mo and is similar to the matrix of the Mo$\mathrm{Fe}-\mathrm{Re}-\mathrm{Cr}$ matrix found in Figure 4.1. Regions labeled 7, 8 and 12 all contain significant levels of $\mathrm{Zr}$ and $\mathrm{Fe}$, indicating each is of the type $\mathrm{Zr}-\mathrm{Fe}-\mathrm{Rh}-\mathrm{Mo}-\mathrm{Ni}$, but explanations for the contrast found in areas labeled 8 and 12, are not straightforward. Perhaps the region labeled 8 defines the interface between $\mathrm{Zr}-\mathrm{Fe}-\mathrm{Rh}-$ Mo-Ni and Mo-Fe-Re-Cr as an array of misfit dislocations, and the region labeled 12 defines the interface between $\mathrm{Zr}-\mathrm{Fe}-\mathrm{Rh}-\mathrm{Mo}-\mathrm{Ni}$ and $\mathrm{Fe}-\mathrm{Mo}-\mathrm{Cr}$. However, it can be noted that the compositions for these features are almost identical.

Further structural analysis of this specimen would provide additional information on the nature of the Moand Re-bearing phases in the metallic waste form. 


\subsection{Discussion}

Four distinct phase fields have been identified the SS-13Mo alloy. These individual regions can be seen in the colorized image in Figure 5-1 where the green is iron, red is molybdenum, and blue is zirconium. It is possible that a fifth phase field exists in the form of equiaxed particles that originally occupied the empty cavities found, but this phase could not be analyzed because it did not remain after specimen preparation. Vibratory polishing and grinding and dimpling procedures left only empty cavities. $\mathrm{The} \mathrm{Zr}$ rich phase (blue region in Figure 5-1) is distributed as fine precipitate, $\sim 10 \mu \mathrm{m}$ in diameter, often coating cavities. A Mo-Fe-Re-Cr lamellar eutectic phase field (red-green region in Figure 5-1) appears as blocky regions $\sim 30 \mu \mathrm{m}$ in diameter, surrounded by a Fe-Mo-Cr lamellar eutectic phase field (light green), and that in turn, is surrounded by a Rh-Ni-Mo-Zr-Fe phase field (dark green). The eutectic phase separation reactions are different. The Mo-Fe-Re-Cr lamellar eutectic appears to be a result of austenitic steel forming at lower volume fraction within an intermetallic phase, whereas the Fe-Mo-Cr lamellar eutectic may be a result of the same intermetallic phase forming within a ferritic steel phase. The missing equiaxed particles, based on the melting points of the elements added, is expected to be rich in $\mathrm{Re}$ $\left(\mathrm{T}_{\mathrm{m}}=3167^{\circ} \mathrm{C}\right)$, Mo $\left(\mathrm{T}_{\mathrm{m}}=2620^{\circ} \mathrm{C}\right)$, and perhaps $\mathrm{Rh}\left(\mathrm{T}_{\mathrm{m}}=1966^{\circ} \mathrm{C}\right)$. However, it is possible that the empty cavities represent bubbles left in the melt. Bubbles, however, are considered less likely because the bubbles are not preferentially distributed near the top of the button where the slag as found. Therefore, it can be anticipated that as the sample solidified, equiaxed particles solidified first, surrounded by a fine $\mathrm{Zr}$ rich precipitate. The Mo-Fe-Re-Cr lamellar eutectic solidified from the melt next, followed by the FeMo-Cr lamellar eutectic. Finally the Zr-Fe-Rh-Mo-Ni phase formed.

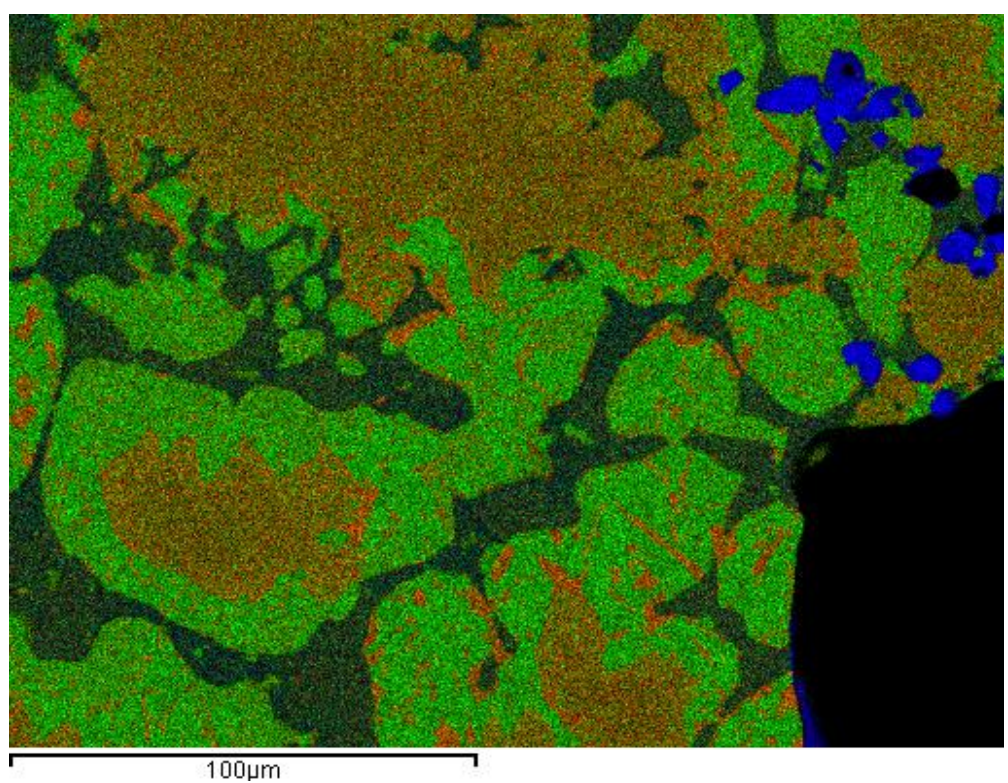

Figure 5-1 Colorized map showing the separation of lamellar eutectic (red-green), Fe-Mo-Cr eutectic (light green), Zr-rich phase (blue), Rh-Ni-Mo-Zr-Fe phase (dark green region, and a pore (black) in the INL Alloy

It is important to identify the disposition of Tc and fission product metal surrogates in the phases formed in relevant alloys and then study solubility in that alloy over range of waste stream compositions. Other waste form durability studies are being conducted to examine the release of radioactive elements from these materials. In the MAWS approach as iron must be added to alloy the waste streams, the use of ferrous sulfamate to reduce transition metal fission products and Fe from added ferrous sulfamate feed may be beneficial to waste form; although, this depends on the ability to remove sulfur before processing. The current predicted waste stream compositions are not amenable to alloying with Zircaloy, so copper or 
iron are under consideration to permit processing at lower temperatures (i.e., $1300^{\circ} \mathrm{C}$ ). However, $\mathrm{Zr}-\mathrm{Cu}$ and $\mathrm{Zr}-\mathrm{Cu}-\mathrm{Fe}$ alloys are dominated by intermetallics that have limited capacity for radionuclides and other waste species. It may also be possible to add a small amount of Zircaloy to form a slag layer to incorporate contaminants that will not dissolve in alloy. For instance, iron oxide $\left(\mathrm{Fe}_{2} \mathrm{O}_{3}\right)$ that forms from incompletely reduced Tc waste stream. 


\subsection{Conclusions}

Four phase fields have been identified in a sample of $316 \mathrm{SS}$ containing $13.2 \mathrm{wt} \% \mathrm{Mo}, 6.2 \% \mathrm{Re}, 5.3 \% \mathrm{Zr}$ and $4.0 \% \mathrm{Rh}$, two of which are lamellar eutectics, with a fifth probably present. The eutectic reactions appear to involve separation of austenitic steel with high Mo from an intermetallic Mo-Fe-Re phase, and the intermetallic Mo-Fe-Re phase from a ferritic steel with low Ni. Knowledge of the microstructure of metallic waste forms assists in the development of these materials and allows for improved understanding of their potential long-term behavior under disposal conditions.

These multi-phase materials require a combination of scanning and transmission electron microscopy analysis, including electron diffraction analysis which was not performed during this investigation. However, characterization studies would be further benefitted from other diffraction methods, including x-ray and neutron, as was done with the EBR-II SS-15Zr alloys. 


\section{References}

Abraham, D. P. and N. L. Dietz, 2002. Role of laves intermetallics in nuclear waste disposal, Materials Science and Engineering, A329-331, 610-615.

Abraham, D. P., J. W. Richardson, and S. M. McDeavitt, 1997. Laves intermetallics in stainless steelzirconium alloys, Materials Science and Engineering, A239-240, 658-664.

Keiser, D. D., D. P. Abraham, and J. W. Richardson, 2000. Influence of technetium on the microstructure of a stainless stee-zirconium alloy, Journal of Nuclear Materials, 277, 333-338.

Jartych, E., M. Karolus, D. Oleszak, and J. K. Zurawicz, 2002. Structure and hyperfine interactions in mechanosynthesized iron-molybdenum alloys, Journal of Alloys and Compounds, 337, 69-75.

Jiang, M., K. Oikawa, T. Ikeshoji, L. Wulff, L., and K. Ishida, 2001. Thermodynamic calculations of Fe-Zr and Fe-Zr-C systems, Journal of Phase Equilibria, 22, 406-417.

McDeavitt, S. M., D. P. Abraham, and J. Y. Park, 1998. Evaluation of stainless steel-zirconium alloys as high-level nuclear waste forms, Journal of Nuclear Materials, 257, 21-34. 
PNNL 18055

\section{Distribution}

No. of

Copies

2 Idaho National Laboratory

P. O. Box 1625

Idaho Falls, ID 83415

Steven Frank

Steven C. Marschman

2 Savannah River National Laboratory

Savannah River Site

Aiken, SC 29808

Robert Sindelar

Marie Kane

2 Los Alamos National Laboratory

P.O. Box 1663

Los Alamos, NM 87545

Gordon Jarvinen

David Kolman

3 Argonne National Laboratory

9700 South Cass Avenue

Argonne, IL 60439

William L. Ebert

Jeffrey A. Fortner

Allen Bakel

1 Prof. Ken Czerwinski

Harry Reid Center for Environmental

Studies

University of Las Vegas

4505 South Maryland Parkway

Las Vegas, NV 89154-4009
No. of

Copies

14 Local Distribution

Pacific Northwest National Laboratory

James E. Buelt

K2-01

Edgar C. Buck (3)

$\mathrm{P} 7-27$

Clark D. Carlson

P7-25

Ruby M. Ermi

P8-15

Dave S. Gelles

P8-15

Brady D. Hanson

P7-27

Edgar R. Gilbert

K8-60

Donald D. Lanning

K8-34

Paul J. MacFarlan

P7-27

Robert J. Seffens

P8-15

Michael W. Urie

P7-27

John D. Vienna 


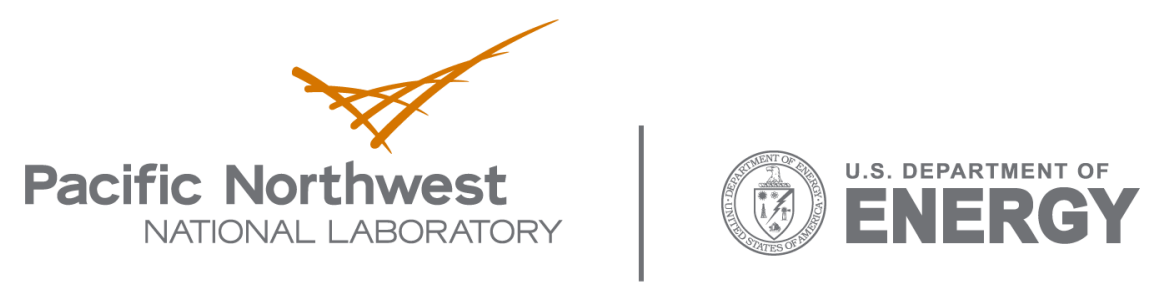

902 Battelle Boulevard

P.O. Box 999

Richland, WA 99352

1-888-375-PNNL (7665)

www.pnl.gov 